Federal Reserve Bank of Dallas

Globalization and Monetary Policy Institute

Working Paper No. 91

http://www.dallasfed.org/assets/documents/institute/wpapers/2011/0091.pdf

\title{
Indeterminacy and Forecastability ${ }^{*}$
}

\author{
Ippei Fujiwara \\ Australian National University \\ Bank of Japan \\ Yasuo Hirose \\ Keio University
}

September 2011

\begin{abstract}
Recent studies document the deteriorating performance of forecasting models during the Great Moderation. This conversely implies that forecastability is higher in the preceding era, when the economy was unexpectedly volatile. We offer an explanation for this phenomenon in the context of equilibrium indeterminacy in dynamic stochastic general equilibrium models. First, we analytically show that a model under indeterminacy exhibits richer dynamics that can improve forecastability. Then, using a prototypical New Keynesian model, we numerically demonstrate that indeterminacy due to passive monetary policy can yield superior forecastability as long as the degree of uncertainty about sunspot fluctuations is relatively small.
\end{abstract}

JEL codes: C53, C62, E17

\footnotetext{
* Ippei Fujiwara, Crawford School of Economics and Government, Lennox Crossing, Building \#132, The Australian National University, Canberra ACT 0200, Australia. Ippei.fujiwara@anu.edu.au. Yasao Hirose, Faculty of Economics, Keio University, 2-15-45 Mita, Minato-ku, Tokyo 108-8345, Japan. yhirose@econ.keio.ac.jp. We have benefited from discussions with Rochelle Edge and Rhys Mendes. The views in this paper are those of the authors and do not necessarily reflect the views of the Bank of Japan, the Federal Reserve Bank of Dallas or the Federal Reserve System.
} 


\section{Introduction}

Recent empirical studies demonstrate that the forecasting performance of macroeconometric models has deteriorated during the Great Moderation. Over the period from the mid-1980s, Atkeson and Ohanian (2001) find that a random walk forecast outperforms the forecasts in the Greenbook and by the backward-looking Phillips curve. Fisher, Liu, and Zhou (2002) and Orphanides and van Norden (2005) confirm this result of poor forecasting performance of Phillips curve models over simple univariate models. D'Agostino, Giannone, and Surico (2006) show that a wider range of time-series forecasting models such as factor-augmented AR models and pooled bivariate models cannot improve on simple univariate models. Faust and Wright (2009) document that forecasting performances improve when the sample before the Great Moderation is included. On the statistical sources of the lack of forecastability during the Great Moderation, Stock and Watson (2007) note that inflation dynamics have become in most part driven by transitory and thus unforecastable component. ${ }^{1}$ Similar conclusions are reported by Tulip (2009) for the Greenbook forecasts and by Trehan (2009) for the Survey of Professional Forecasters.

Why does the transitory component become more dominant than the permanent one during the Great Moderation? Edge and Gurkaynak (2010) argue that this stems from active monetary policy since the mid-1980s. As explicitly shown in Goodfriend and King (2009), when a central bank actively adjusts the nominal interest rate in response to inflation, inflation dynamics become less persistent. In the extreme case where the central bank aims at completely stabilizing inflation, inflation dynamics are solely governed by transitory cost-push shocks. Consequently, under extremely aggressive monetary policy, we lose the forecastability of inflation and so as of other macroeconomic variables. In fact, Estrella (2005) claims that the failure of the term structure to incorporate predictive component of inflation is due to the changes in the U.S. monetary policy.

\footnotetext{
${ }^{1}$ Roberts (2004) finds that the Phillips curve becomes flatter in the mid-1980s and coefficients on the lagged inflation rates changed. Fuhrer, Olivei, and Tootell (2009) also point out the changes in parameters associated with inflation dynamics during the Great Moderation.
} 
These findings about the difficulties in macroeconomic forecasts during the Great Moderation conversely imply that forecastability is higher in the preceding era. This argument is, however, somewhat counterintuitive. It has been documented that the U.S. monetary policy before the 1980s was passive against inflation so that the equilibrium was indeterminate. Clarida, Galí, and Gertler (2000) argue that the U.S. monetary policy during the pre-Volcker era is consistent with indeterminacy based on the GMM estimates of monetary policy rules. Lubik and Schorfheide (2004) reach the same conclusion by estimating a New Keynesian model that allows for both determinacy and indeterminacy. ${ }^{2}$ Under indeterminacy, the economy can be unexpectedly volatile because sunspot shocks, which are non-fundamental beliefs of agents, additionally affect the equilibrium dynamics. Thus, it is not easy to imagine a situation where one can forecast better under indeterminacy.

In contrast to this casual view against the forecastability under indeterminacy, this paper explore the possibility of better forecastability under indeterminacy using dynamic stochastic general equilibrium (DSGE) models. First, we analytically show the case where the equilibrium dynamics of a macroeconomic variable are characterized by an i.i.d. process under determinacy but are characterized by an ARMA process under indeterminacy. The endogenous persistence implied by the ARMA representation can improve forecastability under indeterminacy. Then, using a prototypical New Keynesian model estimated in Lubik and Schorfheide (2004), we demonstrate that the model with passive monetary policy, which leads to indeterminacy, can yield superior forecastability compared to the one with active monetary policy. In addition, we present the possibility that the forecast performance under indeterminacy can be worse when the degree of uncertainty about sunspot shocks is large.

The remainder of this paper proceeds as follows. Section 2 presents a simple example where indeterminacy can result in better forecastability. Section 3 numerically illustrates our argument using a New Keynesian model. Finally, Section 4 concludes.

\footnotetext{
${ }^{2}$ The applications of the methodology proposed by Lubik and Schorfheide (2004) are found in Benati and Surico (2009) and Hirose (2007, 2008, 2010).
} 


\section{Forecastability under Indeterminacy}

To illustrate the forecastability of a DSGE model under indeterminacy, a simple example is presented. Consider the following univariate linear rational expectations model that governs the behavior of an endogenous variable $y_{t}$ :

$$
y_{t}=\frac{1}{\alpha} \mathbb{E}_{t} y_{t+1}+\varepsilon_{t},
$$

where $\mathbb{E}$ denotes the mathematical expectation operator, $\varepsilon_{t} \sim$ i.i.d. $\left(0, \sigma_{\varepsilon}^{2}\right)$ is a fundamental shock, and $\alpha$ is a parameter. Following Sims (2002), we define a rational expectations forecast error $\eta_{t}$ such that

$$
y_{t}=\mathbb{E}_{t-1} y_{t}+\eta_{t}
$$

Then, the system is expressed as

$$
\mathbb{E}_{t} y_{t+1}=\alpha \mathbb{E}_{t-1} y_{t}-\alpha \varepsilon_{t}+\alpha \eta_{t}
$$

If $\alpha>1$, a unique non-explosive solution exists when $\mathbb{E}_{0} y_{1}=0$ and $\varepsilon_{t}+\eta_{t}=0$. Then, the solution under determinacy is of the form:

$$
y_{t}=\varepsilon_{t}
$$

which implies that $y_{t}$ follows the i.i.d. process.

If $\alpha \leq 1$, on the other hand, the stability requirement imposes no restriction on the rational expectations forecast error $\eta_{t}$. In this case, following Lubik and Schorfheide $(2003,2004), \eta_{t}$ can be expressed as a linear combination of the fundamental shock $\varepsilon_{t}$ and a vector of sunspot shocks $\zeta_{t}$ :

$$
\eta_{t}=\tilde{M} \varepsilon_{t}+M_{\zeta} \zeta_{t}
$$

where both $\tilde{M}$ and $M_{\zeta}$ are arbitrary parameters, unrelated to $\alpha$. The vector of sunspot shocks $\zeta_{t}$ consists of non-fundamental disturbances that include self-fulfilling beliefs of agents. For simplicity, we define a reduced form sunspot shock $\zeta_{t}^{*}=M_{\zeta} \zeta_{t}$ with the dimension of the sunspot shocks being unity. Then, the solution under indeterminacy is given by the following $\operatorname{ARMA}(1,1)$ representation:

$$
y_{t}=\alpha y_{t-1}+\tilde{M} \varepsilon_{t}-\zeta_{t}^{*}-\alpha \varepsilon_{t-1} .
$$


Therefore, $y_{t}$ in equation (2) exhibits richer dynamics than that in equation (1). In particular, endogenous persistence implied by equation (2) can help replicate the sample properties of data in the period before the Great Moderation, and hence the forecast performance based on this solution can be improved.

$\alpha$ is a key parameter to contribute to higher forecastability since it characterizes the persistence of the dynamic behavior of $y_{t}$. On the other hand, uncertainty about the sunspot shock $\zeta_{t}^{*}$ potentially disturb forecasting under indeterminacy. If the variance of $\zeta_{t}^{*}$ is relatively small compared to $\alpha$, forecastability becomes higher under indeterminacy even though the additional non-fundamental disturbance comes into effect in the equilibrium dynamics. In what follows, we examine how results can change with different degree of uncertainty about the sunspot shock using a sylized DSGE model.

\section{Numerical Illustration}

\subsection{The Model}

We consider a prototypical New Keynesian monetary DSGE model estimated in Lubik and Schorfheide (2004): ${ }^{3}$

$$
\begin{gathered}
\tilde{y}_{t}=\mathbb{E}_{t} \tilde{y}_{t+1}-\sigma^{-1}\left(\tilde{r}_{t}^{n}-\mathbb{E}_{t} \tilde{\pi}_{t+1}\right)+g_{t}, \\
\tilde{\pi}_{t}=\beta \mathbb{E}_{t} \tilde{\pi}_{t+1}+\kappa\left(\tilde{y}_{t}-z_{t}\right), \\
\tilde{r}_{t}^{n}=\rho_{r} \tilde{r}_{t-1}^{n}+\left(1-\rho_{r}\right)\left[\psi_{\pi} \tilde{\pi}_{t}+\psi_{y}\left(\tilde{y}_{t}-z_{t}\right)\right]+\varepsilon_{r, t}, \quad \varepsilon_{r, t} \sim \text { i.i.d. } N\left(0, \sigma_{r}^{2}\right),
\end{gathered}
$$

where $\tilde{y}_{t}$ denotes the percentage deviation of output from a trend path, and $\tilde{\pi}_{t}$ and $\tilde{r}_{t}^{n}$ are the percentage deviations of inflation and the short-term nominal interest rate from their steady-state values.

Equation (3) is a dynamic IS equation obtained from the optimality conditions for households' utility maximization. $g_{t}$ captures the net effects of exogenous shifts on their preferences, which we call a demand shock. $\sigma$ is the inverse of intertemporal

\footnotetext{
${ }^{3}$ The detailed description of the model is found in such standard textbooks as Woodford (2003), Galí (2008) and Walsh (2010).
} 
substitution elasticity. Equation (4) is the New Keynesian Phillips curve derived from profit maximization of monopolistically competitive firms that face a Calvo (1983)style nominal rigidity. $z_{t}$ represents exogenous changes in the marginal costs of production. $\beta$ is the subjective discount factor, and $\kappa$ is a function of the probability that firms can re-optimize their prices and the households' preference parameters. Equation (5) is a Taylor (1993) style monetary policy rule. $\varepsilon_{r, t}$ is interpreted as an unsystematic component of monetary policy. $\rho_{r}$ is the policy smoothing parameter, whereas $\psi_{\pi}$ and $\psi_{y}$ are the degrees of policy responses to inflation and the output gap.

Both $g_{t}$ and $z_{t}$ evolve according to the following $\mathrm{AR}(1)$ processes:

$$
\begin{aligned}
& g_{t}=\rho_{g} g_{t-1}+\varepsilon_{g, t}, \quad \varepsilon_{g, t} \sim \text { i.i.d. } N\left(0, \sigma_{g}^{2}\right), \\
& z_{t}=\rho_{z} z_{t-1}+\varepsilon_{z, t}, \quad \varepsilon_{z, t} \sim \text { i.i.d. } N\left(0, \sigma_{z}^{2}\right),
\end{aligned}
$$

where we assume that the innovations, $\varepsilon_{r, t}, \varepsilon_{g, t}$ and $\varepsilon_{g, t}$, are uncorrelated with each other.

\subsection{Solution under Indeterminacy}

The preceding equations can be written as the following linear rational expectations system:

$$
\Gamma_{0}(\theta) s_{t}=\Gamma_{1}(\theta) s_{t-1}+\Psi(\theta) \varepsilon_{t}+\Pi(\theta) \eta_{t},
$$

where $s_{t}=\left[\tilde{y}_{t}, \tilde{\pi}_{t}, \tilde{r}_{t}^{n}, g_{t}, z_{t}, \mathbb{E}_{t} \tilde{y}_{t+1}, \mathbb{E}_{t} \tilde{\pi}_{t+1}\right]^{\prime}, \varepsilon_{t}=\left[\varepsilon_{g, t}, \varepsilon_{z, t}, \varepsilon_{r, t}\right]^{\prime}$, and $\eta_{t}=\left[\eta_{t}^{y}, \eta_{t}^{\pi}\right]^{\prime}=$ $\left[\tilde{y}_{t}-\mathbb{E}_{t-1} \tilde{y}_{t}, \tilde{\pi}_{t}-\mathbb{E}_{t-1} \tilde{\pi}_{t}\right]^{\prime} . \Gamma_{0}, \Gamma_{1}, \Psi$ and $\Pi$ are the conformable matrices that depend on the vector of structural parameters $\theta$.

According to Lubik and Schorfheide (2003), a full set of solutions is of the form:

$$
s_{t}=\Gamma^{*}(\theta) s_{t-1}+\Psi^{*}(\theta, \tilde{M}) \varepsilon_{t}+\Pi^{*}\left(\theta, M_{\zeta}\right) \zeta_{t},
$$

where $\zeta_{t}$ is a vector of sunspot shocks. Whereas the coefficient matrix $\Gamma^{*}$ depends exclusively on $\theta, \Psi^{*}$ and $\Pi^{*}$ depend on the arbitrary matrices, $\tilde{M}$ and $M_{\zeta}$, respectively, as well as $\theta$. 
We specify a particular solution as in Lubik and Schorfheide (2003). First, we choose $\tilde{M}$ such that the contemporaneous impact of the fundamental shocks is continuous on the boundary of determinacy and indeterminacy regions. Second we impose the normalization $M_{\zeta}=1$ with the dimension of the sunspot shocks being unity. For notational simplicity, we rewrite the particular solution as

$$
s_{t}=\Phi_{1} s_{t-1}+\Phi_{\varepsilon} \varepsilon_{t}+\Phi_{\zeta} \zeta_{t}
$$

where $\zeta_{t} \sim$ i.i.d. $N\left(0, \sigma_{\zeta}^{2}\right)$.

\subsection{Data and Forecasting Procedure}

The data used for our analysis are the same as Lubik and Schorfheide (2004). Observed output deviations from trend, inflation, and interest rates are stacked in the vector $Y_{t}$. The measurement equations that relate $Y_{t}$ to the vector of model variables $s_{t}$ are given by

$$
Y_{t}=A_{0}+A_{1} s_{t}
$$

where

$$
A_{0}=\left[\begin{array}{c}
0 \\
\pi^{*} \\
\pi^{*}+r^{*}
\end{array}\right], \quad A_{1}=\left[\begin{array}{ccccccc}
1 & 0 & 0 & 0 & 0 & 0 & 0 \\
0 & 4 & 0 & 0 & 0 & 0 & 0 \\
0 & 0 & 4 & 0 & 0 & 0 & 0 \\
0 & 0 & 0 & 0 & 0 & 0 & 0 \\
0 & 0 & 0 & 0 & 0 & 0 & 0 \\
0 & 0 & 0 & 0 & 0 & 0 & 0 \\
0 & 0 & 0 & 0 & 0 & 0 & 0
\end{array}\right],
$$

and $\pi^{*}$ and $r^{*}$ are the steady-state inflation rate and real interest rate respectively.

The measurement equations (7) together with the law of motion (6) for $s_{t}$ constitute a state-space model for the observables $Y_{t}$. The Kalman filter is used to compute the filtered latent series $s_{t}$.

Let $H$ denote a forecast horizon. For each $t$, forecasting starts from the filtered variables $s_{t}$ and we draw random sequences $\left\{\varepsilon_{t+1}^{(i)}, \ldots, \varepsilon_{t+H}^{(i)}\right\}$ and $\left\{\zeta_{t+1}^{(i)}, \ldots, \zeta_{t+H}^{(i)}\right\}$ from the distributions specified above. We then iterate the equations (6) and (7) forward 
Table 1: Parameter setting

\begin{tabular}{ccccccccccccc}
\hline \hline$\sigma$ & $\kappa$ & $\psi_{\pi}$ & $\psi_{y}$ & $\rho_{r}$ & $\rho_{g}$ & $\rho_{z}$ & $r^{*}$ & $\pi^{*}$ & $\sigma_{r}$ & $\sigma_{g}$ & $\sigma_{z}$ & $\sigma_{\zeta}$ \\
\hline 1.00 & 0.33 & 0.95 & 0.125 & 0.50 & 0.50 & 0.50 & 0.92 & 4.56 & 0.23 & 0.27 & 1.13 & 0.20 \\
\hline
\end{tabular}

to construct

$$
s_{t+h \mid t}^{(i)}=\Phi_{1} s_{t+h-1 \mid t}^{(i)}+\Phi_{\varepsilon} \varepsilon_{t+h}^{(i)}+\Phi_{\zeta} \zeta_{t+h}^{(i)}
$$

and

$$
Y_{t+h \mid t}^{(i)}=A_{0}+A_{1} s_{t+h \mid t}^{(i)}
$$

for $h=1, \ldots, H$. This process is repeated for $i=1, \ldots, I$, and the mean forecast $\hat{Y}_{t+h \mid t}$ is obtained by averaging the $Y_{t+h \mid t}^{(i)} \mathrm{s}$.

\subsection{Parameters}

Table 1 summarizes the baseline parameters. The inverse of intertemporal substitution elasticity $(\sigma=1)$ and the slope of the Phillips curve $(\kappa=0.33)$ are in line with the parameter values used in standard textbooks such as Galí (2008) and Walsh (2010). Following Lubik and Schorfheide (2003), we parameterize the inflation coefficient $\left(\psi_{\pi}=0.95\right)$ in the monetary policy rule so that equilibrium indeterminacy arises due to passive monetary policy. The output gap coefficient in the policy rule $\left(\psi_{y}=0.125\right)$ follows from the original Taylor (1993) rule. The policy smoothing parameter, $\rho_{r}$, and the autoregressive coefficients for demand and cost shocks, $\rho_{g}$ and $\rho_{z}$, are all fixed at 0.5 . The standard deviation of the shocks $\left(\sigma_{r}=0.23, \sigma_{g}=0.27\right.$, $\sigma_{z}=1.13$, and $\left.\sigma_{\zeta}=0.20\right)$ are set according to the posterior mean estimates in Lubik and Schorfheide (2004).

\subsection{Results}

We evaluate the forecastability of the New Keynesian model under indeterminacy in terms of four-period-ahead forecasts for the percentage deviations of output from 
Table 2: RMSE comparison

\begin{tabular}{ccccc}
\hline \hline & Baseline & $\psi_{\pi}=1.05$ & $\sigma_{\zeta}=0.5$ & $\sigma_{\zeta}=0.7$ \\
\hline RMSE for output (\%) & 1.91 & 1.88 & 1.92 & 1.92 \\
\hline RMSE for inflation (\%) & 2.81 & 3.45 & 3.15 & 4.07 \\
\hline
\end{tabular}

Note: RMSEs for four-period-ahead forecasts of output and inflation are computed recursively with data from 1960:1 to 1979:2.

the trend and of inflation from the steady-state. Table 2 shows the root mean square errors (RMSEs) in the pre-Volcker sample (1960:1 to 1979:2) in four parameter settings: baseline (the parameters presented above), the case of determinacy $\left(\psi_{\pi}=\right.$ $1.05)$, the cases of more uncertainty due to sunspots $\left(\sigma_{\zeta}=0.5\right.$ and $\left.\sigma_{\zeta}=0.7\right)$. We focus on the RMSEs for inflation because the RMSEs for output are almost the same across the parameter settings.

A remarkable finding here is that the model under indeterminacy exhibits a better forecast performance than the model under determinacy. Yet, at the same time, the economy under indeterminacy can be unexpectedly volatile due to sunspot shocks. Such an uncertainty potentially makes the forecast more difficult. The last two columns in Table 2 demonstrate this point; i.e., the increased volatilities in the sunspot shock lead to the larger RMSEs. In particular, when the standard deviation of the sunspot shock increased to 0.7 , the forecast performance becomes worse than that under determinacy.

\section{Conclusion}

Indeterminacy implies that economy can fluctuate with non-fundamental sunspot shocks. This, however, does not necessarily worsen the forecastability. Thanks to the endogenous persistence stemming from indeterminacy, the forecasting performance of DSGE models can improve under indeterminacy, as long as the degree of uncertainty about sunspot shocks is relatively small. 


\section{References}

Atkeson, Andrew, and Lee E. Ohanian (2001). "Are Phillips Curves Useful for Forecasting Inflation?." Quarterly Review, 25(1), 2-11.

Benati, Luca, and Paolo Surico (2009). "VAR Analysis and the Great Moderation." American Economic Review, 99(4), 1636-1652.

Calvo, Guillermo A. (1983). "Staggered Prices in A Utility-Maximizing Framework." Journal of Monetary Economics, 12(3), 383-398.

Clarida, Richard, Jordi Galí, and Mark Gertler (2000). "Monetary Policy Rules and Macroeconomic Stability: Evidence and Some Theory." Quarterly Journal of Economics, 115(1), 147-180.

D'Agostino, Antonello, Domenico Giannone, and Paolo Surico (2006). "(Un)Predictability and Macroeconomic Stability." Working Paper Series 605, European Central Bank.

Edge, Rochelle M., and Refet S. Gurkaynak (2010). "How Useful Are Estimated DSGE Model Forecasts for Central Bankers?." Brookings Papers on Economic Activity, 41(2), 209-259.

Estrella, Arturo (2005). "Why Does the Yield Curve Predict Output and Inflation?." Economic Journal, 115(505), 722-744.

Faust, Jon, and Jonathan H. Wright (2009). "Comparing Greenbook and Reduced Form Forecasts Using a Large Realtime Dataset." Journal of Business 86 Economic Statistics, 27(4), 468-479.

Fisher, Jonas D. M., Chin Te Liu, and Ruilin Zhou (2002). "When Can We Forecast Inflation?." Economic Perspectives, (1Q), 32-44.

Fuhrer, Jeff, Giovanni Olivei, and Geoffrey M. B. Tootell (2009). "Empirical Estimates of Changing Inflation Dynamics." Working Papers 09-4, Federal Reserve Bank of Boston. 
Galí, Jordi (2008). Monetary Policy, Inflation, and the Business Cycle: An Introduction to the New Keynesian Framework. Princeton: Princeton University Press.

Goodfriend, Marvin, and Robert G. King (2009). "The Great Inflation Drift." NBER Working Papers 14862, National Bureau of Economic Research, Inc.

Hirose, Yasuo (2007). "Sunspot Fluctuations under Zero Nominal Interest Rates." Economics Letters, 97(1), 39-45.

Hirose, Yasuo (2008). "Equilibrium Indeterminacy and Asset Price Fluctuation in Japan: A Bayesian Investigation." Journal of Money, Credit and Banking, 40(5), 967-999.

Hirose, Yasuo (2010). "Monetary Policy and Sunspot Fluctuations in the U.S. and the Euro Area." Macroeconomic Dynamics, forthcoming.

Lubik, Thomas A., and Frank Schorfheide (2003). "Computing Sunspot Equilibria in Linear Rational Expectations Models." Journal of Economic Dynamics and Control, 28(2), 273-285.

Lubik, Thomas A., and Frank Schorfheide (2004). "Testing for Indeterminacy: An Application to U.S. Monetary Policy." American Economic Review, 94(1), 190217.

Orphanides, Athanasios, and Simon van Norden (2005). "The Reliability of Inflation Forecasts Based on Output Gap Estimates in Real Time." Journal of Money, Credit and Banking, 37(3), 583-601.

Roberts, John M. (2004). "Monetary Policy and Inflation Dynamics." Finance and Economics Discussion Series 2004-62, Board of Governors of the Federal Reserve System.

Sims, Christopher A. (2002). "Solving Linear Rational Expectations Models." Computational Economics, 20(1-2), 1-20.

Stock, James H., and Mark W. Watson (2007). "Why Has U.S. Inflation Become Harder to Forecast?." Journal of Money, Credit and Banking, 39(s1), 3-33. 
Taylor, John B. (1993). "Discretion versus Policy Rules in Practice." CarnegieRochester Conference Series on Public Policy, 39, 195-214.

Trehan, Bharat (2009). "Survey Measures of Expected Inflation and the Inflation Process.” Working Paper Series 2009-10, Federal Reserve Bank of San Francisco.

Tulip, Peter (2009). "Has the Economy Become More Predictable? Changes in Greenbook Forecast Accuracy." Journal of Money, Credit and Banking, 41(6), $1217-1231$.

Walsh, Carl E. (2010). Monetary Theory and Policy. Cambridge: The MIT Press, 3 edn.

Woodford, Michael (2003). Interest and Prices: Foundations of a Theory of Monetary Policy. Princeton: Princeton University Press. 